\title{
The added value of knowledge management systems to the organization's performance and efficiency over the existing information systems
}

\author{
Fadi Al-qudah $^{1}$, SohairAL-hakeem ${ }^{2}$, Walid Bani-Hani ${ }^{2}$ \\ ${ }^{1}$ Department of Business Administration , Taibah University,Al-Madinah al-Munawwarah -KSA \\ ${ }^{2}$ Department of information system, higher colleges of technology(UAE)
}

\begin{abstract}
:
Information systems are widely used in organizations and play a very important role in improving an organization's performance. In recent years knowledge management has become an important issue for managers, consultants and researchers. This paper describes definition and attribution of management information system and knowledge management. It clarifies points like data, information, process, information systems, management information systems and knowledge management system. The approach of this research is to analyze both systems in order to identify their role in an organization, the relationship between them, discover common and uncommon features between the two systems, determine the added value of knowledge management system to the organization's performance and efficiency over the existing information system and to find out when an information system becomes a knowledge management system and when it is useful to implement the latter
\end{abstract}

Keywords: Expert System; knowledge management systems (KMS); Management Information System (MIS); Information Systems (IS);Big data.

\section{Introduction}

Organization's Managers and consultants turn their focus to computerized solution assist in increasing organization's economic and innovative performance and fulfill manager's daily task. As a result Information and Communication Technology has grown to achieve unanticipated levels of sophistication. Information is frequently said to be the glue that holds an organization together [12]. Nowadays information systems play a very important role in improving an organization's performance and its increased competitive capacity. Therefore, it is essential for organizations to decide what are the most important business processes and core competencies that have to be supported by an information system, and what kind of information system has to be implemented and conforms to the organization's requirements [8].

There is a growing consensus that the effective and productive management of knowledge is a critical factor for the success of an organization. Knowledge is a most valuable strategic resource that requires renewal constantly. Yet not many organizations have started building their capacity to manage knowledge [7]. This growing realization of knowledge as the source of sustainable competitive advantage quickly popularized knowledge management (KM)[24]. Knowledge is quite different from data and information in nature, although sometimes people use the three terms interchangeably [19].

Information systems (IS) and management of knowledge are often discussed either as separate entities or alternatively as analogies [10]. In this paper a distinction will be made between information system and knowledge

management and discussion of the values knowledge management and knowledge management systems added to the organization's performance in term of economic and efficiency.

\section{What is MIS}

Information Systems (IS) are more than just a computer hardware and software. Effective usages of IS require understanding of the organization, management, and information technology that shape a system [6]. A Management Information System (MIS) is generally thought of as an integrated system 
providing information to support operations, management and decision-making functions in an organization [2]. The increasing interest in MIS had led to much activity in developing techniques and software for data management. MIS is basically concerned with the process of collecting, processing, storing and transmitting relevant information to support the management operations in any organizations [14]. Therefore, IS are organizational and management solutions based on information technology (IT), to challenges posed by the business environment

\section{WHAT KM And KMS}

There is no agreed definition of "knowledge management", even among practitioners. The term is used loosely to refer to a broad collection of organizational practices and approaches related to generating, capturing, and disseminating know-how and other content relevant to the organization's business [13]. At its 4th Annual Conference on Knowledge Management held in Washington, D.C. in May 2002, the American Productivity and Quality Association (APQC) echoed the sentiments spoken by Mrs. Bush when it defined the goal of KM: Connecting people to the best practices, knowledge, and expertise they need to create value. In another works KMS is a set of processes which Creates, gathers, stores, maintains, and disseminates knowledge.

Knowledge management (KM) is an effort to increase useful knowledge within the organization. Ways to do this include encouraging communication, offering opportunities to learn, and promoting the sharing of appropriate knowledge artifacts [15]. An emerging information systems discipline that specializes in the distribution of knowledge, or expertise, throughout the enterprise, where it's needed, when it's needed. Process Knowledge Management specifically refers to the sharing of process knowledge across the organization, so that the best practice, or optimum process, for any task can be accessed with no intermediary steps. As a result, many organizations have begun to re-examine and renovate their business strategies, processes, information technologies and organizational structures from knowledge management prospective.

\section{KMS vs MIS}

During the last two decades, knowledge management has often been associated with computers and information systems [23].
Management Information system can be described as delivering the right information to the right people at the right time with the right form. Knowledge management can be illustrated as getting the right people to have the right conversation at the right time [12]. With the growing strategic importance of Knowledge Management (KM) and Knowledge Management Systems (KMS) in organizations, more firms are implementing KMS, a class of information systems applied to managing organizational knowledge [3]. The early emphasis in knowledge management was on information systems. Then the focus shifted towards organizational development, intellectual capital management, and Competence management [17]. To differentiate the management of information from the management of knowledge, one must examine the distinctions drawn between the related concepts: data information, knowledge and intelligence.[16]. This aspect of the relationship between data, information, and knowledge is represented in Figure 1 [4,25].

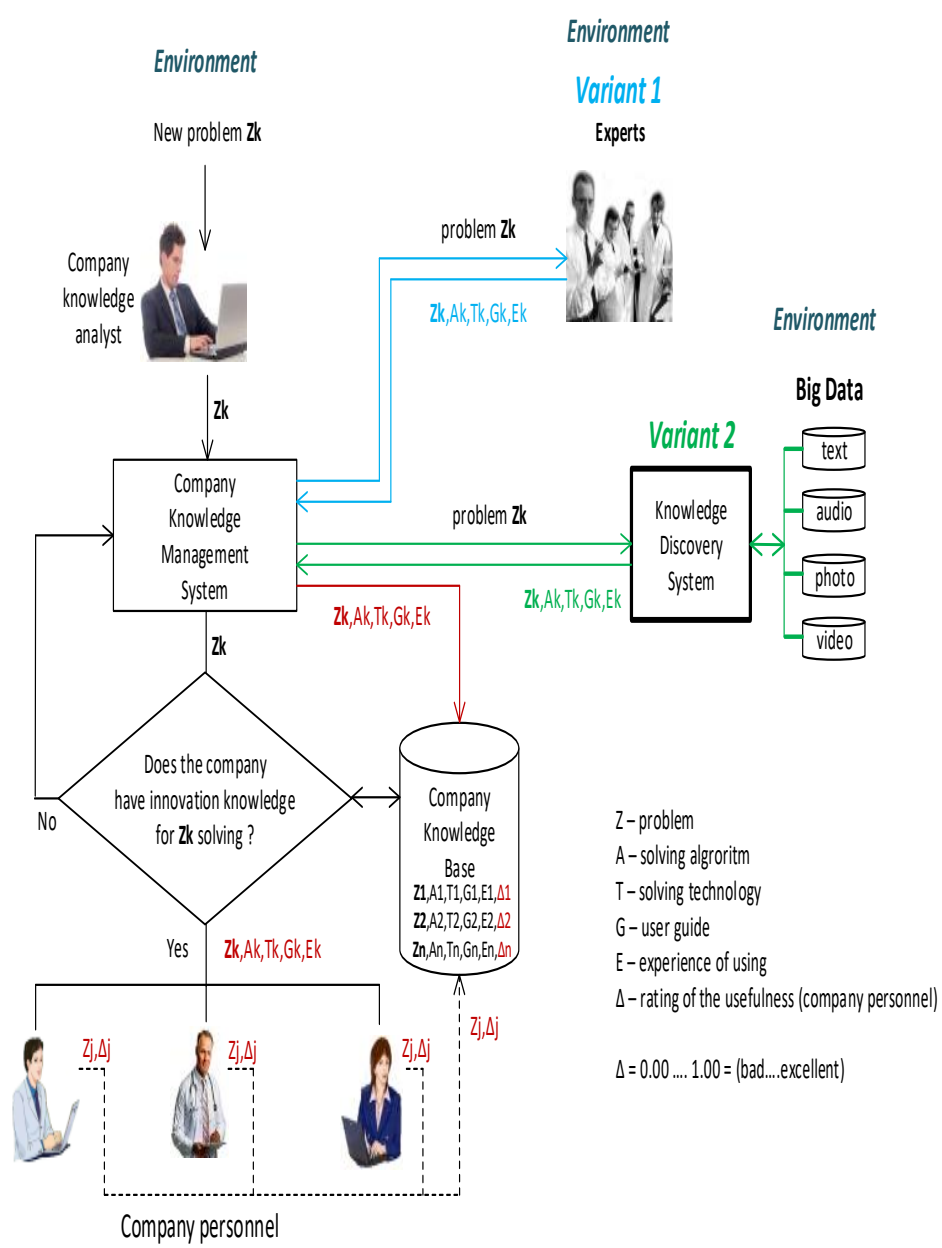

Figure 1: Relationship between the key components of the information system and knowledge management system 


\section{The border between KMS and MIS}

Processing data can be performed by machine, but only the human mind can process knowledge or even information [9]. An overview of the relationship between the key components of the information system and knowledge management system is shown in Figure 2. The process from data capture through data processing to the use of information is shown in the dotted line area to the left (information management). The databases, documents and the experience of individuals -the components of knowledge management - are shown to the right [21].

\section{Impact of MIS on organizations}

In his paper [22] has summarize MIS advantages to an organization

- Users can quickly and timely access information since information is systematically stored by using computer systems and computer networks.

- MIS support executives making decision, setting and adjusting strategies and operational plans. They summarize and analyze information. So, executives can easily apply it

- Good MIS will show how an operation accords to an organization goal. It's adopted to monitor an operation.

- MIS reduce organizations' cost because of time, labor and expenses reducing in long run.

\section{Impact of MIS on organizations}

In his paper [22] has summarize MIS advantages to an organization

- Users can quickly and timely access information since information is systematically stored by using computer systems and computer networks.

- MIS support executives making decision, setting and adjusting strategies and operational plans. They summarize and analyze information. So, executives can easily apply it

- Good MIS will show how an operation accords to an organization goal. It's adopted to monitor an operation.

- MIS reduce organizations' cost because of time, labor and expenses reducing in long run.

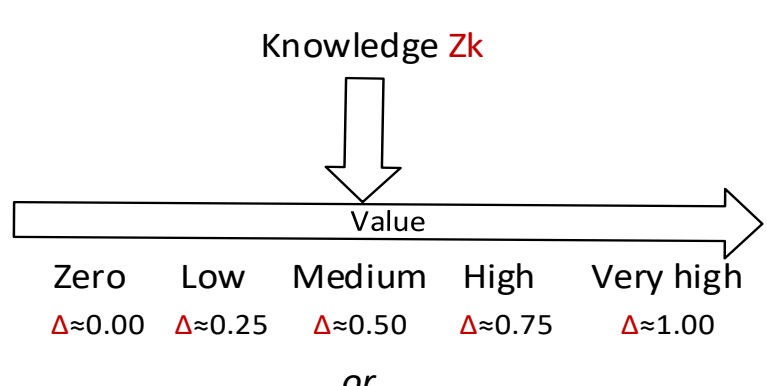

$\Delta \approx 0.00-0.24 \quad \Delta \approx 0.25-0.49 \quad \Delta \approx 0.50-0.74 \quad \Delta \approx 0.75-0.99 \quad \Delta \approx 1.00$

$$
\text { Value }=f(\text { Zk real profitability })
$$

Figure 2: Relationship between data, information, and knowledge

\section{Impact of MIS on organizations}

In his paper [22] has summarize MIS advantages to an organization

- Users can quickly and timely access information since information is systematically stored by using computer systems and computer networks.

- MIS support executives making decision, setting and adjusting strategies and operational plans. They summarize and analyze information. So, executives can easily apply it

- Good MIS will show how an operation accords to an organization goal. It's adopted to monitor an operation.

- MIS reduce organizations' cost because of time, labor and expenses reducing in long run.

\section{Impact of KMS on organizations}

Organizations that try to management their knowledge resources and processes are today common phenomena. As a general term, knowledge management $(\mathrm{KM})$ is used to describe such efforts and the information systems that are used to support $\mathrm{KM}$ processes are called knowledge management systems (KMS)[7]. Knowledge Management Systems (KMS), as a special kind of information system, is no different to an "intangible" asset.

For this reason, we propose to measure the impact of these KMS at a different level in order to facilitate and isolate the effects of implementing knowledge management systems [20].

Knowledge management plays a major part in increasing organizations innovativeness. Innovations are key drivers of growth and development of modern organizations. KMS help organizations develop in accordance with the changes and requirements of their environment in order to 
increase business efficiency and maintain business activities in the market arena[5].

With the growing strategic importance of Knowledge Management (KM) and Knowledge Management Systems (KMS) in organizations, more firms are implementing KMS, "a class of information systems applied to managing organizational knowledge" [3]. Even many government and non-for-profit organizations are beginning to recognize the potential value in implementing and using a KMS [11].

\section{Conclusions}

One of the most important issues discussed in the paper was about the impact of knowledge management on organizations performance and efficiency A comprehensive review of theory, research, and practices on knowledge management was conducted. A deep analysis and classification was per-formed. As a main conclusion, based on the performed classification and analysis of the Existing works:

- Knowledge management is a new form of management information system

- In the literature KM was de-scribed as an asset to organization. Organizational knowledge management enables the organization to create value.

- It is important to implement KMS to cope with competence

- Knowledge management can pro-vide a birdseye view of cur-rent processes and practice and their corresponding strength and weaknesses.

- Knowledge management pro-vides continuous learning which can help organization effectively and successfully manage their key information and knowledge assets.

- KMS develop more effective extranets to encourage interactive working with Partners and clients.

- Implementing a new KMS pro-vides support to real time reporting on budgets, resources and audit progress.

- Discussion about ISs and KM continually follows the rationalistic paradigm. Human thinking with practical and strategic skills and the ability to learn are far from the knowledge model of ISs. KM systems are efficient and effective only when used right. IS content shall not be perceived as a substitute for human knowledge. Knowledge and information should not be managed in similar manners [18].
- The creation of knowledge can be supported in a network, being a place where people from various positions and spheres of experience can create a very innovative environment $[1,25]$.

- Better and accurate understanding of the relevance of knowledge and knowledge management is expected to contribute to more effective business strategies that result in sustained organization performance.

Results from this study suggest that managers can leverage their best innovation by matching the implementation of KMS with organization context.

Despite its ever increasing interest and importance, there are no formal methodologies for KMS, and the scale of this problem in large organizations is such that most existing tools cannot be applied in their current implementation

\section{References}

[1] Aidemark, J. 2018. Strategic planning of knowledge management system: A problem exploration approach. Ph.D. thesis, computer and systems science.

[2] Ajayi, I. A. and Omirin, F. F. 2017. The use of management information systems (MIS) in decision making in the South-West Nigerian Universities. Educ. Res. Rev. J., 2, pp: 109116.

[3] Alavi, M. and Leidner, D. E. 2016. Review $\mathrm{KM}$ and KM systems: Conceptual foundations and research issues', MIS Quarterly Journal, Vol. 25, pp. 107-136

[4] Gonzalez A. Sabherwal Becerra-Fernandez, I., Knowledge Management: Systems and Processes

[5] Bojan, K. and Bojan, P. 2012. The role of knowledge management in increasing enterprise's innovativeness, Series:Economics and Organization Vol. 9, No1, pp. $93-110$

[6] Chen, J. C. 2018. Introduction to management information system, power points slides, online.

[7] Choi, B. 2002. Knowledge management enablers, processes, and organi-zational performance, Ph.D. thesis.

[8] Galandere, I. and Vinogradova, V. 2005. Where is the border between an information system and a knowledge management 
system? International Research Journal. 3(2), pp.179-196.

[9] Shera, J. 2015. in Machlup and Mansfield's The Study of Information: Interdisciplinary Messages. NY: Wiley.

[10] Meriluoto, J. 2017. Knowledge management and information system. knowldege board, online,

[11] Ko, Do. Gil. and Dennis, A. R. 2013. Profiting from knowledge management:the effects of knowledge management system use on sales performance, online.

[12] Kotler, P. and Caslione, J. A. 2016. The business of managing and marketing in the age of turbulence, America: AMACOM.

[13] Thapa, k. 2010. Knowledge management a tool for exploring skills and increasing benefits., online, October 2010.

[14] Laudon, K. and J. Laudon. 2009. Management Information Systems. Prentice Hall, Upper Saddle River, New Jersey

[15] McInerney, C. 2002. Knowledge management and the dynamic nature of knowledge. Journal of the American Society for Information Science and Technology (JASIST), 53(12), 1009-1018

[16] Meadow, C. T., Boyce, B.R. and Kraft, D. H. 2000. Text information retrieval systems, $2^{\text {nd }}$ edition. San Diego, CA: Academic Press.

[17] Moballeghi, M. and Moghaddam, G. G. 2008. Knowledge management and information systems, online,.

[18] Meriluoto, J. 2016. Knowledge management and information systems, online, June 2006, jnkping international business school, jnkping university.

[19] Pusaksrikit, P. 2006. How does knowledge management improve the service industry, jnkping international business school.

[20] Robles-Flores, J. A. 2014. Knowledge management systems and their impact on knowledge-intensive business processes, online, Octubre 2004.

[21] Schmitt, K. and Sallee, K. 2012. Information and knowledge management in nature conservation.

[22] Tawata, A. 2016. Management information system: definition and attribution, Online.
[23] Tuomi, I. 2002. the future of knowledge management. lifelong learning in europe (LLinE), vol VII, issue 2/2002, pp. 69-79.

[24] Joint Inspection Unit. 2014. Knowledge management at the international labour organization, report, 2004

[25] Shakah, G, Krasnoproshin, V. Valvachev, A. 2012. Monitoring and Management of Natural Territorial Complexes journal of Advances in Computing. 2(1):1-5

[26] Shakah ,G. A New Method for Solving Hard Diagnosis Problems, Computer Engineering And Intelligent System, 2018. pp, 13-19

[27] Yasser MAl-Sharo, Ghazi Shakah, Classification of big data: machine learning problems and challenges in network intrusion prediction, International Journal of Engineering \& Technology, 7 (4) (2018) 3865-3869.

[28] Ghazi Shakah, The problem of image segmentation and de-noising methods and various approaches to its solution, international journal of engineering \& technology Vol 7, No 4 (2018)

[29] Ricardo,Colomo-

Palacios.Eduardo,Fernandes. A case analysis of enabling continuous software deployment through knowledge management

[30] International Journal of Information Management Volume 40, June 2018, Pp.186-189 